\title{
A responsabilidade social de siderúrgicas mineiras e a percepção de suas comunidades de entorno
}

\author{
Marcelo Aureliano Monteiro de Andrade ${ }^{\mathrm{a} *}$, Marlusa Gosling ${ }^{\mathrm{b}}$, Ricardo Vinícius Dias Jordão \\ a*aureliano.marcelo@yahoo.com.br, UFMG, Brasil \\ ${ }^{b}$ mg.ufmg@gmail.com, UFMG, Brasil \\ cjordaoconsultor@yahoo.com.br, FPL, Brasil
}

\begin{abstract}
Resumo
Este estudo analisou as percepções que comunidades de três grandes siderúrgicas mineiras têm sobre a responsabilidade social dessas organizações, assim com a relação disso com o valor da marca (VM). 0 estudo se baseou na Pirâmide de responsabilidade social de Carroll (1991) e foi feito a partir de um método tipo Survey. Foi estruturado um questionário com afirmações do tipo likert que procurou avaliar como as comunidades percebem as organizações do ponto de vista dos vários aspectos da responsabilidade social corporativa, de acordo com o modelo de Carroll (1991), assim como qual a percepção de marca que essas pessoas têm dessas corporações e a relação desses fatores. Os resultados foram analisados por meio de métodos estatísticos multivariados e demonstram que as empresas têm alto VM entre suas comunidades de entorno e que isso é construído principalmente em função de uma percepção positiva das dimensões éticas e filantrópicas.
\end{abstract}

Palavras-chave

Valor de marca. Responsabilidade social.

\section{Introdução}

0 debate sobre a responsabilidade social corporativa (RSC) tem raízes na década de 1930 mas intensificou-se a partir dos anos 1950 (CARROLL, 1999). Apesar disso, ainda não há um consenso sobre o real significado da RSC (CARROLL, 1999; SERPA, 2006). É importante para a compreensão desse fenômeno, no entanto, destrinchar um pouco suas raizes históricas. Conforme Tenório (2006), visão compartilhada por Carroll (1999), o desenvolvimento da RSC tem a ver com a combinação de uma série de elementos que precisam ser vistos em conjunto. 0 primeiro deles relaciona-se com a falência do estado de bem-estar social, especialmente nas décadas de 1970 e 1980, que deixou de prover, nos países onde esse sistema de fato funcionou, garantias sociais às populações. Outras questões, contudo, também ajudaram a construir o painel atual sobre o assunto. Dentre as mais importantes, destacam-se: os problemas de ordem ambiental que acentuaram-se nas últimas décadas; o desenvolvimento de novas mídias; o aumento de escolaridade e consciência da população, especialmente

em países de alto desenvolvimento humano; dentre outros. Esses fatores em conjunto ocasionaram uma pressão sobre as empresas para que elas adotassem posturas mais responsáveis e, consequentemente, propiciaram o ambiente ideal para o desenvolvimento dos conceitos e estratégias de RSC.

No Brasil, apenas a partir da década de 1990 a academia passou a produzir consideravelmente sobre RSC (TENÓRIO, 2006; GUIMARÃES, 2006; OLIVEIRA, 2005; SOARES, 2004), pois a partir dessa década esse paradigma passou a ser adotado de forma recorrente por organizações do país, especialmente por grandes corporações. Mesmo que não haja consenso, a maior parte da literatura sugere que uma organização socialmente responsável atua de forma ética com todos os seus públicos de relacionamento e respeitando os limites ecológicos para as atividades produtivas, independentemente das razões que a levem a agir assim (ASHLEY, 2002; WILKIE; MOORE, 1999; BORGES, 2001).

*UFMG, Belo Horizonte, MG, Brasil Recebido 15/03/2011; Aceito 28/09/2012 
A noção de responsabilidade social empresarial decorre da compreensão de que a ação empresarial deve, necessariamente, buscar benefícios para a sociedade, propiciar a realização profissional dos empregados, promover benefícios para os parceiros e para o meio ambiente e trazer retorno para os investidores. A adoção de uma postura clara e transparente no que diz respeito aos objetivos e compromissos éticos da empresa fortalece a legitimidade social de suas atividades, refletindo-se positivamente no conjunto de suas relações (ETHOS, 2000, apud TENÓRIO, 2006, p. 7).

Um dos motivos para a falta de consenso é a divergência que se tem sobre o princípio norteador dessas políticas (CARROLL, 1999). Conforme Tenório (2006), a RSC deve funcionar, além das motivações econômicas e ligadas à competitividade das empresas, a partir de um princípio ético dos gestores, portanto a partir da preocupação dessas pessoas com o bem alheio e a natureza.

Outra vertente, defendida pela maior parte dos autores analisados e provavelmente pela maioria (inclusive os autores deste artigo), atualmente, pondera que dificilmente a RSC ocorre por altruísmo e princípio ético de gestores, tendo em vista as motivações econômicas das empresas (ADKINS, 2005; SOARES, 2004). Parece haver uma tendência de perceber que as empresas assumem ações socialmente responsáveis como parte de estratégias voltadas a fortalecer a imagem corporativa junto a stakeholders (SROUR, 2003; ADKINS, 2005). Essa realidade tem inclusive pressionado as organizações, especialmente as de grande porte, a divulgarem maciçamente ações socialmente responsáveis, a fim de que todos saibam o que tem sido feito e para que isso agregue valor à imagem da empresa que está anunciando (OLIVEIRA, 2005; TREVISAN, 2002).

A RSC, nessa perspectiva, é entendida como um instrumento útil para a geração de ganhos no longo prazo, que se justifica pelas exigências e pelas pressões que os diversos públicos de relacionamento vêm fazendo sobre as empresas para que elas distribuam melhor seus ganhos. A organização agora tem de lidar com "múltiplos objetivos" para sua sobrevivência e não apenas com o objetivo econômico (TOFFLER, 1995). Assim, mesmo que se observe, por parte das organizações privadas, um discurso de preocupação cada vez mais intenso com questões éticas, com a natureza e com a qualidade de vida de seus stakeholders, a real motivação nessa perspectiva é a vantagem competitiva por meio do reforço da imagem (BITTENCOURT; CARRIERI, 2005; SOARES, 2004).

Este artigo apresenta uma pesquisa que teve como objeto de estudo três grandes empresas siderúrgicas do estado de Minas Gerais. Buscou-se observar como as comunidades de entorno dessas empresas percebem-nas do ponto de vista da RSC e a relação disso com o valor de marca (VM) dessas firmas, também de acordo com a percepção das comunidades - conforme será visto adiante, o valor de marca nesse caso só poderia ser medido nessa esfera. Foi avaliado também, a partir de um estudo prévio dessas instituições (ANDRADE; GOSLING; XAVIER, 2010), se a percepção das comunidades é compatível com os objetivos da comunicação corporativa de duas dessas empresas.

Salienta-se que em MG as siderúrgicas têm grande impacto social e econômico. Em 2007, entre as 20 maiores empresas do estado cinco eram do ramo siderúrgico, inclusive as duas maiores (JORNAL..., 2007). Além disso, em MG, a prática da RSC, apontada como um dos pilares da competitividade empresarial (FEDERAÇÃO..., 2009), e sua divulgação têm sido bastante observadas e estimuladas entre as indústrias.

0 presente artigo foi estruturado em cinco seções, incluindo a introdução. Na seção 2, discute-se a RSC como instrumento de marketing social, imagem e VM. Posteriormente, na seção 3, descreve-se a metodologia da pesquisa. Na seção 4 apresentam-se os resultados da pesquisa e sua análise. Por fim, na seção 5 , as conclusões são destacadas de acordo com os objetivos pretendidos, seguidas das referências bibliográficas.

\section{Estratégia mercadológica, imagem de marca e responsabilidade social corporativa}

0 entendimento do conceito de imagem é necessário para a compreensão do conceito de valor de marca que visa, em geral, a uma imagem favorável da empresa perante seus diversos públicos. Para Lindquist (1975), a imagem, do ponto de vista organizacional, é aquilo que sentem e pensam as pessoas sobre uma marca de produto ou institucional. Esse autor salienta que esse processo é subjetivo, por depender do observador e da organização que transmite a imagem, e composto por uma combinação de elementos simbólicos, cognitivos, emocionais e funcionais. A imagem que os diversos públicos têm sobre uma organização pode ser definida, portanto, pelas atitudes e comunicações dessa empresa com seus stakeholders, assim como pelo contexto em que os diferentes públicos e as empresas se inserem.

Segundo Keller (1993), as organizações devem trabalhar o fortalecimento de suas marcas e, consequentemente, de sua imagem por meio de diversas iniciativas, como a utilização de materiais publicitários diversos, a fabricação de produtos de boa qualidade, a realização de uma distribuição satisfatória e o oferecimento de produtos e serviços a um preço justo. Todas essas iniciativas, em conjunto, podem ser feitas com a intenção de se criar uma marca de alto valor para empresas, clientes e demais stakeholders. 
Salienta-se que o valor, nesse caso, é aquele percebido pelo público - interno ou externo - como consequência da entrega de um número alto de benefícios a um custo satisfatório.

Lassar, Mittal e Sharma (1995), na busca por um modelo em que se possa averiguar se uma marca alcançou ou não um nível de alto valor na mente do consumidor, também chamado de Brand Equity, propuseram cinco aspectos que devem ser avaliados em relação às marcas: performance (desempenho), que avalia se a marca garante ao cliente um desempenho de alto nível e superior à concorrência; social image (imagem social), que mede a reputação da marca, assim como o nível de envolvimento dos clientes; value (valor), que avalia se os clientes consideram o preço pago compatível com os benefícios que são entregues, ou mesmo se superam as expectativas iniciais; trustworthiness (confiança), parâmetro do nivel de confiança que os clientes depositam na marca; e attachment (afeto), que diz respeito à quantidade de sentimentos positivos que os clientes têm em relação à marca, ou seja, o nível de afeição das pessoas em relação à marca. De acordo com esses autores, uma marca se torna uma Brand Equity quando consegue ser avaliada em alto nível nesses cinco aspectos.

Esses conceitos ganham importância quando se pensa em RSC como elemento de reforço de imagem e de valor de marca. As estratégias de responsabilidade social podem ser vistas, sob essa lógica, como um importante meio para o fortalecimento das marcas.

Destaca-se que alguns autores, como Jones (1980), defendem que só podem ser consideradas como socialmente responsáveis ações praticadas para o bem de stakeholders e que não visam ao retorno financeiro. Por outro lado, outros, como Carroll (1983, 1999), ponderam que a RSC pode trazer boas oportunidades de fortalecimento da marca corporativa e que isso pode ajudar no retorno financeiro. Esse autor traz outra perspectiva ao tema ao afirmar que a lucratividade da organização é um dos pilares da RSC, tendo em vista que sem ganho financeiro a responsabilidade social não se sustenta. Drucker (1984) compartilha dessa ideia, acrescentando que a RSC deve ser vista como oportunidade de negócio.

Carroll (1991) ressalta que, para que as empresas sejam socialmente responsáveis, quatro dimensões devem ser levadas em consideração: a econômica, que diz respeito à responsabilidade da empresa na manutenção de suas finanças saudáveis; a legal, que aborda o compromisso organizacional de obedecer às leis vigentes; a ética, que trata a responsabilidade de a empresa ser justa em seus relacionamentos públicos; e a filantrópica, que diz respeito à necessidade de a empresa ser altruísta com pessoas e grupos de relacionamento necessitados. Para o autor, não há RSC se as quatro dimensões não estiverem preenchidas, pois cada público de relacionamento demanda ações que se enquadram em pelo menos uma delas. Apesar disso, as dimensões são dispostas em uma pirâmide, pelo nível de importância que cada uma tem na sobrevivência de uma empresa no curto, médio e longo prazos. Na base, ficam a dimensão econômica (DE) e a legal (DL), já que o seguimento de seus preceitos é essencial para a sustentação da organização, especialmente no curto prazo. No meio superior, situa-se a dimensão ética (DET) e, no topo, a filantrópica (DF). Apesar das duas últimas serem essenciais para que uma organização se constitua como socialmente responsável, elas não impactam tanto na sustentabilidade da empresa no curto prazo, embora tenham grande relevância para o sucesso no médio e longo prazo, conforme o autor.

Dessa forma, Carroll (1991) dividiu as demandas dos diferentes públicos, sejam internos ou externos, dentro dos quatro pilares da pirâmide. Assim, acionistas e empregados, por exemplo, demandarão da empresa, dentre outras coisas, retorno econômico, enquanto a comunidade demandará, dentre outras, obras assistenciais e equilíbrio ecológico. 0 autor pondera que essas dimensões são dinâmicas, que se complementam e que todas têm importância no contexto da RSC - mesmo que muitas vezes existam conflitos entre elas, especialmente entre a dimensão econômica e as demais.

\section{Metodologia da pesquisa}

A pesquisa deste trabalho consiste em um estudo empírico, do tipo descritivo e de natureza quantitativa. Buscou-se verificar a percepção das comunidades de entorno de três empresas siderúrgicas do estado de Minas Gerais sobre a RSC dessas firmas e a relação dessa percepção com a imagem de marca das siderúrgicas, também de acordo com a visão das comunidades. Foram utilizados para isso levantamentos estatísticos feitos a partir de um questionário estruturado. Segundo Laville e Dione (2007), essa abordagem justifica-se por permitir uma maior capacidade de generalizações. As três siderúrgicas, situadas entre as 20 maiores empresas de MG - com base no levantamento do Jornal Estado de Minas (JORNAL..., 2007) -, foram denominadas EMPRESA A, EMPRESA B e EMPRESA C, já que não foram informadas sobre a realização da pesquisa.

0 questionário foi estruturado a partir das quatro dimensões da RSC de Carroll (1991) - DE, DL, DET e DF -, utilizadas para medir a imagem que as comunidades de entorno de cada empresa têm sobre os aspectos da RSC dessas organizações, e também a partir dos conceitos afeto (AM), decorrente do estudo de Lassar, Mittal e Sharma (1995), e qualidade percebida (QUA), dos estudos de Yoo e Donthu (2001). 0 primeiro quesito (AM) se refere aos sentimentos que clientes têm em relação à determinada marca 
e o segundo (QUA), ao valor de uma marca entre consumidores a partir de três construtos: Lealdade, Qualidade Percebida e Associações e Lembranças relativas à marca. Destaca-se que o valor de marca neste caso foi considerado apenas em função de fatores não funcionais, tendo em vista que as pessoas desses locais praticamente não possuem relação de consumidor direto das siderúrgicas.

0 Quadro 1 apresenta afirmações do questionário aplicado e respectivos indicadores - cada dimensão foi verificada como um construto, a partir de quatro ou três afirmativas do tipo likert.

A investigação aconteceu entre os meses de junho e agosto de 2008 nas redondezas das três empresas e em horário comercial. Os dados foram coletados por meio de um questionário com 23 afirmações do tipo Likert, com escala variando entre 1 e 7 . A pesquisa foi do tipo Survey, com vistas a analisar duas premissas e quatro hipóteses. As premissas analisadas foram: P1: As comunidades de entorno percebem que a DET e a DF são melhor preenchidas pelas empresas que as demais, corroborando com o divulgado por essas organizações - de acordo com o estudo prévio (ANDRADE; GOSLING; XAVIER, 2010); e P2: As organizações siderúrgicas analisadas têm alto VM entre suas comunidades de entorno. As hipóteses submetidas a teste empírico neste estudo foram as seguintes: H1: Existe um impacto positivo da DE sobre o VM; H2: Existe um impacto positivo da DL sobre o VM; H3: Existe um impacto positivo da DET sobre o VM; e H4: Existe um impacto positivo da DF sobre o VM.

A definição da amostra para cada empresa foi de acordo com o número de parâmetros do questionário, tendo em vista que não foram encontrados dados secundários sobre a população que vive, trabalha e estuda ao redor das siderúrgicas. Assim, seguiu-se a recomendação de Hair et al. (1998), de buscar 10 respondentes para cada variável independente utilizada nas equações estruturais, o que corresponde a 230 pessoas, mas optou-se por recolher uma amostra mínima de 300 respondentes por organização, para minimizar as margens de erro e aumentar a fidedignidade (foram coletados 309 questionários da EMPRESA A, 307 da EMPRESA B e 303 da EMPRESA C). Salienta-se que a seleção da amostra, segundo a classsificação de Laville e Dione (2007), é não probabilística, feita por conveniência, uma vez que as pesquisas aconteceram nas ruas das comunidades, principalmente em escolas e no comércio. Destaca-se que só podiam responder o questionário aqueles que preenchiam pelo menos um dos seguintes requisitos: trabalhar na empresa; morar ou trabalhar próximo à empresa; ter parentesco com algum funcionário. Foram também feitas três perguntas de ordem demográfica (escolaridade, sexo e idade), mas essas

Quadro 1. Afirmações do questionário e respectivos indicadores.

\begin{tabular}{|l|l|}
\hline \multicolumn{1}{|c|}{ CóDIG0 } & \multicolumn{1}{|c|}{ Afirmações } \\
\hline V001_DEper1 & 1) A empresa $X$ busca sempre maximizar seus lucros. \\
\hline V002_DEper2 & 2) A empresa $X$ busca controlar firmemente seus custos de produção. \\
\hline V003_DEper3 & 3) A empresa $X$ planeja seu sucesso no longo prazo. \\
\hline V004_DEper4 & 4) A empresa $X$ sempre aumenta seus lucros. \\
\hline V005_DLper1 & 5) A empresa $X$ garante que seus funcionários trabalhem dentro dos padrões definidos por lei. \\
\hline V006_DLper2 & 6) A empresa $X$ não infringe seus contratos. \\
\hline V007_DLper3 & 7) A empresa $X$ cumpre a legislação mesmo que isso prejudique seu desempenho econômico ou produtivo. \\
\hline V008_DLper4 & 8) A empresa $X$ sempre se submete aos princípios legais. \\
\hline V009_DETper1 & 9) A empresa $X$ atua de forma justa com todos, mesmo que isso prejudique seu desempenho econômico. \\
\hline V010_DETper2 & 10) A empresa $X$ garante que o respeito a princípios éticos tenha prioridade sobre o desempenho econômico. \\
\hline V011_DETper3 & 11) A empresa $X$ é comprometida com princípios éticos bem definidos. \\
\hline V012_DETper4 & 12) A empresa $X$ evita comprometer padrões éticos para alcançar seus objetivos financeiros e produtivos. \\
\hline V013_DFper1 & 13) A empresa $X$ ajuda a solucionar problemas sociais. \\
\hline V014_DFper2 & 14) A empresa $X$ participa de projetos da comunidade. \\
\hline V015_DFper3 & 15) A empresa $X$ aloca recursos para atividades de ajuda à comunidade. \\
\hline V016_DFper4 & 16) A empresa $X$ tem um papel na nossa comunidade que vai além da mera geração de lucros. \\
\hline V017_AMper1 & 17) Eu gosto muito da empresa $X$. \\
\hline V018_AMper2 & 18) Eu tenho impressões positivas a respeito da empresa X. \\
\hline V019_AMper3 & 19) Eu sinto afeição pela empresa X. \\
\hline V020_QuaComper1 & 20) A empresa X é de alta qualidade. \\
\hline V021_QuaComper2 & 21) A probabilidade de que a empresa X seja confiável é alta. \\
\hline V022_QuaComper3 & 22) A empresa $X$ é honesta. \\
\hline V023_QuaComper4 & 23) A empresa $X$ é muito íntegra. \\
\hline
\end{tabular}

Fonte: Dados da pesquisa. 
não foram correlacionadas ao restante do estudo. A conjugação dessas variáveis originou o modelo de análise utilizado na pesquisa, descrito na Figura 1.

Os dados foram analisados com o auxílio dos softwares SPSS e AMOS. As avaliações dos dados demográficos e dos vínculos dos respondentes com as empresas foram feitas resumidamente, sendo referentes apenas à amostra total, compreendendo 919 questionários. Já as análises das outras 23 variáveis aconteceram a partir de métodos de estatística multivariada. Neste estudo, seguindo as recomendações de Hair et al. (1998), foram utilizadas a análise fatorial exploratória e a análise fatorial confirmatória, a partir de equações estruturais. Realizou-se ainda um pré-teste do instrumento de coleta de dados, a partir dos 100 primeiros exemplares respondidos, que apresentou parâmetros satisfatórios - assim, o questionário ficou inalterado.

Finalmente, aplicou-se o modelo descrito na Figura 1, visando analisar as correlações entre as dimensões da RSC e o VM das organizações, sendo este um construto de segunda ordem gerado pelos construtos de primeira ordem afeto e qualidade.

\section{Apresentação e análise dos dados}

No momento anterior ao teste do modelo foram efetivadas análises iniciais com estimativas básicas das variáveis por grupo, por meio de uma análise de estatísticas descritivas (HAIR et al., 1998), apresentadas na Tabela 1. Posteriormente analisaram-se gráficos dos quartis observados e dos esperados sob a suposição de uma distribuição normal, conhecidos como gráficos Q-Q plot (PESTANA; GAGEIRO, 2000). Nesse quesito, foram analisados (1) histogramas para verificação da dispersão dos dados e (2) gráficos Q-Q visando à análise da normalidade. Finalmente, procedeu-se à análise do modelo estrutural, por meio de técnicas de estatística multivariada.

A análise preliminar mostrou que a idade média dos respondentes girava em torno de 27 anos, com preponderância do sexo feminino, $60 \%$ na amostra. Além disso, 61\% dos entrevistados tinham parentesco direto com algum funcionário e foi observado um grau de escolaridade relativamente elevado: mais de 90\% tinham o Ensino Médio incompleto ou mais. 0 percentual de pessoas que eram vizinhas às usinas foi de 64\%. Já o percentual de entrevistados que eram ou já tinham sido empregados é pequeno, cerca de 10\%.

Na Tabela 1, nota-se que a EMPRESA A apresenta as menores médias, demonstrando que sua imagem frente à comunidade é de menor qualidade em relação às outras firmas. Por isso, foram realizados testes para averiguar quais diferenças de médias foram estatisticamente significativas, aplicando-se o teste t-student para amostras independentes. Os resultados indicaram que a EMPRESA C, de um modo geral, possui médias superiores às EMPRESAS A e B. 0 mesmo aconteceu quando se comparou a EMPRESA B à EMPRESA A. Observou-se que a média de respostas

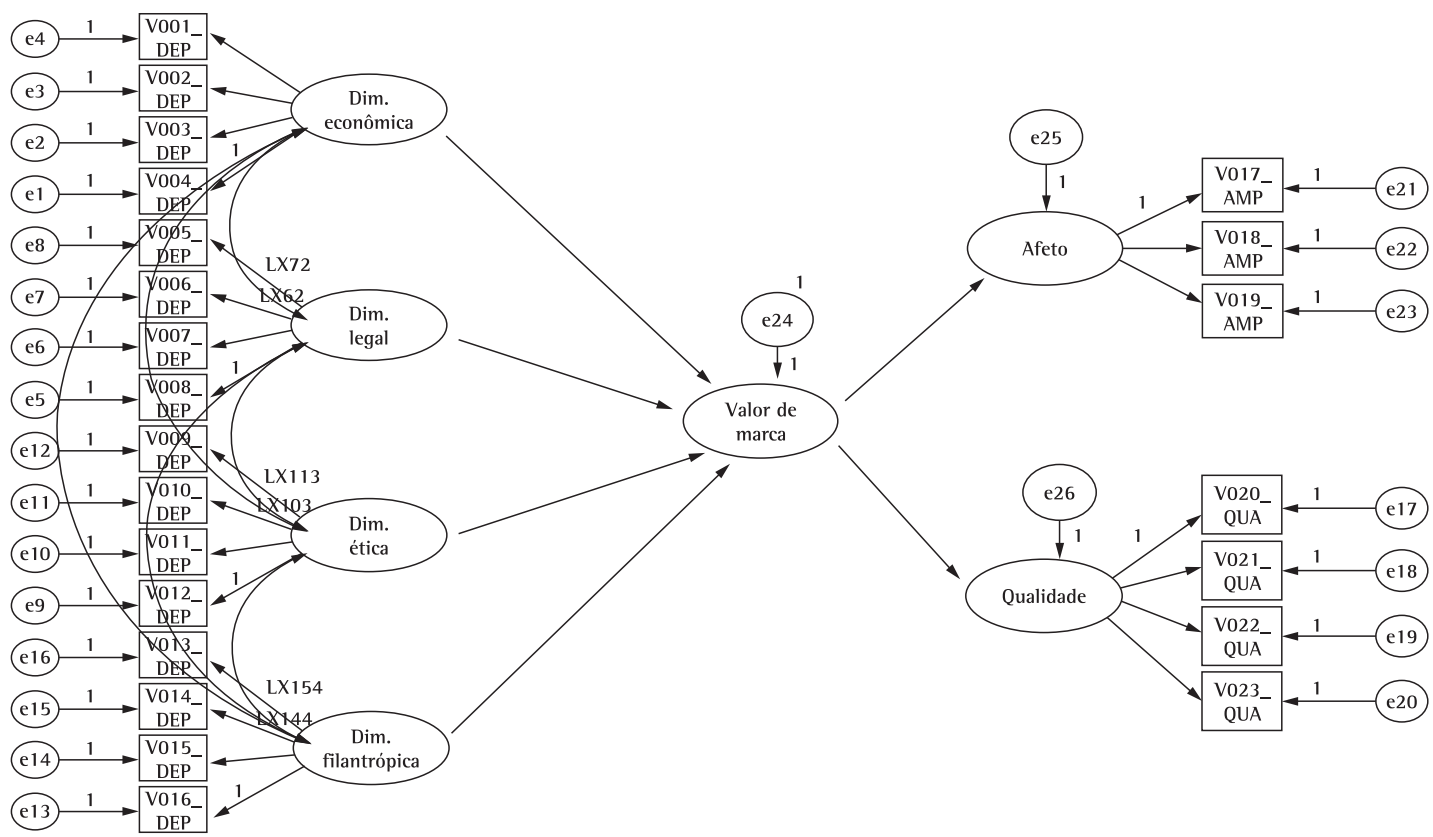

Figura 1. llustração do modelo estrutural testado. Fonte: Dados da pesquisa. 
das variáveis da dimensão econômica da EMPRESA A é significativamente menor que as das demais organizações. Os dados ausentes foram menores que $1 \%$ do total, o que impossibilita a análise do grau de aleatoriedade deles (os questionários foram conferidos pelo pesquisador no momento do seu preenchimento). Tais dados, por serem poucos e dispersos, foram repostos pelo método de regressão. As mudanças nas matrizes de variância e covariância, bem como nas médias, foram imperceptíveis, justificando que tal método não gerou distorções relevantes.

Quando um estudo pretende generalizar resultados de uma amostra à população é necessário fazer suposições sobre a forma como se comporta a distribuição das variáveis estudadas (HAIR et al., 1998). A suposição e forma de relacionamento mais amplamente aplicada é a distribuição normal, que é a base da maioria dos testes e técnicas estatísticas aplicados na área de marketing (TABACHNICK; FIDELL, 2001). Como tal premissa seria fundamental, aplicou-se um procedimento de averiguação desse pressuposto, iniciado pela análise gráfica em que se notaram desvios significativos da normalidade.

Em gráficos dessa natureza, a presença de uma tendência linear formando um ângulo de aproximadamente $45^{\circ}$ entre os valores observados e os esperados sob a suposição de normalidade - com valores dispersos de maneira aleatória ao longo da tendência linear - demonstra uma evidência favorável à normalidade dos dados. A partir desse parâmetro percebeu-se que os gráficos de distribuição das subamostras e global mostraram desvios consideráveis da distribuição normal pela presença de padrões que apresentaram vieses na linha de regressão. Além disso, aplicados testes Kolmogorov-Smirnov de normalidade, os desvios mostraram-se expressivos em todas as subamostras e variáveis, indicando não ser a normalidade um pressuposto possível de atender.

Levando-se em conta que houve desvios da normalidade univariada, foram automaticamente violados os pressupostos de normalidade multivariada (MINGOTI, 2005). Por outro lado, considerando-se que o tamanho da amostra em cada grupo é superior a 200, os problemas de normalidade tendem a reduzir-se (TABACHNICK; FIDELL, 2001). Assim, como nenhuma transformação seria efetiva para melhorar os problemas de normalidade (HAIR et al., 1998), considerando-se o tamanho moderado das amostras e que os vieses obtidos são relativamente pequenos quando se empregam métodos de máxima verossimilhança, aplicou-se esse procedimento no momento de analisar o modelo hipotético de pesquisa.

Tabela 1. Estatísticas descritivas dos indicadores dos construtos nas empresas e global.

\begin{tabular}{|c|c|c|c|c|c|c|c|c|c|}
\hline & \multirow{3}{*}{ Afirmações (indicadores) } & \multicolumn{8}{|c|}{ Grupo } \\
\hline & & \multicolumn{2}{|c|}{ Empresa A } & \multicolumn{2}{|c|}{ Empresa B } & \multicolumn{2}{|c|}{ Empresa C } & \multicolumn{2}{|c|}{ Total } \\
\hline & & M & $\mathrm{S}$ & M & $\mathrm{S}$ & M & $\mathrm{S}$ & $\mathrm{M}$ & $\mathrm{S}$ \\
\hline \multirow{4}{*}{ ص ص } & Afirmação 1 & 5,41 & 1,74 & 6,09 & 1,41 & 6,14 & 1,39 & 5,88 & 1,55 \\
\hline & Afirmação 2 & 5,54 & 1,69 & 6,03 & 1,45 & 5,95 & 1,48 & 5,84 & 1,56 \\
\hline & Afirmação 3 & 5,36 & 1,94 & 6,00 & 1,50 & 5,97 & 1,57 & 5,78 & 1,71 \\
\hline & Afirmação 4 & 5,80 & 1,68 & 6,33 & 1,25 & 6,10 & 1,39 & 6,08 & 1,46 \\
\hline \multirow{4}{*}{$\overrightarrow{0}$} & Afirmação 5 & 5,57 & 1,87 & 5,51 & 1,72 & 5,93 & 1,58 & 5,67 & 1,73 \\
\hline & Afirmação 6 & 4,69 & 1,91 & 4,96 & 1,80 & 5,32 & 1,67 & 4,99 & 1,81 \\
\hline & Afirmação 7 & 4,43 & 1,89 & 4,49 & 1,87 & 4,93 & 1,81 & 4,61 & 1,87 \\
\hline & Afirmação 8 & 5,00 & 1,86 & 5,35 & 1,58 & 5,60 & 1,53 & 5,32 & 1,68 \\
\hline \multirow{4}{*}{$\begin{array}{l}\leftarrow \\
\square\end{array}$} & Afirmação 9 & 4,40 & 1,88 & 3,99 & 1,93 & 4,57 & 1,93 & 4,32 & 1,93 \\
\hline & Afirmação 10 & 4,94 & 1,85 & 4,78 & 1,77 & 5,17 & 1,65 & 4,96 & 1,76 \\
\hline & Afirmação 11 & 5,06 & 1,77 & 5,17 & 1,72 & 5,39 & 1,62 & 5,21 & 1,71 \\
\hline & Afirmação 12 & 4,90 & 1,97 & 4,77 & 1,93 & 5,04 & 1,83 & 4,90 & 1,91 \\
\hline \multirow{4}{*}{$\frac{I}{0}$} & Afirmação 13 & 4,72 & 1,96 & 5,12 & 1,78 & 5,38 & 1,73 & 5,07 & 1,85 \\
\hline & Afirmação 14 & 4,93 & 2,07 & 5,47 & 1,77 & 5,95 & 1,48 & 5,45 & 1,83 \\
\hline & Afirmação 15 & 4,74 & 2,07 & 5,08 & 1,78 & 5,62 & 1,57 & 5,14 & 1,85 \\
\hline & Afirmação 16 & 4,83 & 2,06 & 5,43 & 1,77 & 5,44 & 1,59 & 5,23 & 1,84 \\
\hline \multirow{3}{*}{$\begin{array}{l}\stackrel{2}{\supset} \\
\precsim\end{array}$} & Afirmação 17 & 4,81 & 1,99 & 4,98 & 1,88 & 5,11 & 1,79 & 4,97 & 1,89 \\
\hline & Afirmação 18 & 5,50 & 1,85 & 5,47 & 1,69 & 5,48 & 1,67 & 5,48 & 1,74 \\
\hline & Afirmação 19 & 4,84 & 1,97 & 4,87 & 1,89 & 5,18 & 1,81 & 4,96 & 1,90 \\
\hline \multirow{4}{*}{$\sum_{\ll}$} & Afirmação 20 & 5,87 & 1,56 & 6,25 & 1,20 & 6,09 & 1,30 & 6,07 & 1,37 \\
\hline & Afirmação 21 & 5,58 & 1,69 & 5,76 & 1,42 & 5,96 & 1,38 & 5,76 & 1,51 \\
\hline & Afirmação 22 & 5,14 & 1,74 & 5,02 & 1,66 & 5,57 & 1,43 & 5,25 & 1,63 \\
\hline & Afirmação 23 & 5,13 & 1,74 & 5,16 & 1,58 & 5,60 & 1,48 & 5,30 & 1,62 \\
\hline
\end{tabular}

Fonte: Dados da pesquisa; obs.: M média; $\mathrm{S}$ desvio padrão. 
A partir da constatação de que os dados do estudo não seguem uma distribuição normal, aplicou-se para classificação de outliers o critério usualmente empregado em boxplots - em que casos fora dos limites de [Q1-1,5xIQR ; Q3+1,5xIQR] são considerados extremos para determinada variável (Q1 e Q3 são quartis de ordem 25\% e 75\%, respectivamente e $1 Q R=Q 3-Q 1$ ). Usando esse critério, foram encontrados 1,02\%, 2,71\% e 3,14\% da base de outliers para a EMPRESA A, EMPRESA B e EMPRESA C, respectivamente. Quando se considerou a base agregada de respondentes não houve mudanças em termos da quantidade de casos extremos. Como os outliers foram dispersos entre variáveis e observações, não se considera prudente a exclusão pura e simples dos casos. Por esse motivo, seguiu-se a sugestão de Kline (1998): para ele, casos extremos em escalas do tipo likert podem ser transformados para casos menos influentes. Para tanto, modificam-se os valores observados das escalas para o limite que caracterizaria o caso como outlier, para solucionar o problema dos casos extremos univariados, e nos casos multivariados emprega-se a distância de Mahalanobis ( $\left.\mathrm{D}^{2}\right)$. Dessa forma, valores mais distantes que 55 pontos do centróide $\left(\mathrm{D}^{2}>55\right)$ foram classificados como extremos multivariados. Usando esse critério foram encontrados 14, 13 e 17 casos extremos multivariados para a EMPRESA A, a EMPRESA B e a EMPRESA C, respectivamente. Assim, preferiu-se manter um maior número de observações na amostra analisada e verificar se os resultados com e sem tais observações extremas implicavam em diferenças notáveis em termos de estimativas dos modelos estruturais. Aplicando-se o coeficiente de correlação entre as variáveis e fazendo-se uma inspeção visual em 30 diagramas de dispersão selecionados de maneira aleatória foram detectados ajustes lineares aceitáveis e que desvios da linearidade não foram perceptíveis para a maior parte das variáveis analisadas, evidência considerada positiva.

Quando se buscou identificar se ocorreram problemas de multicolinearidade, avaliou-se o grau de redundância por meio de medidas de inflação da variância (VIF), mas não foram encontrados valores de $\mathrm{VIF}$ que ultrapassassem o limite de 10 pontos sugerido para medidas tradicionais. Observou-se, também, que nenhuma correlação na matriz ultrapassou o limite de 0,90.

Considerando que problemas e distorções nos dados de um estudo podem acarretar vieses nas conclusões, observou-se a recomendação usual de Hair et al. (1998) e de Tabachnick e Fidell (2001) de avaliar condições e pressupostos antes de realizar a análise foco do estudo. Assim, primeiramente analisaram-se características básicas dos dados e na sequência a fidedignidade das medições e do instrumento de pesquisa. Na análise de médias e desvios padrão dos construtos de primeira ordem observou-se que: (1) a média das respostas referentes à DE apresentou-se alta para as três organizações; (2) a variação de respostas foi pequena nos três casos; (3) as demais dimensões também demonstraram resultados elevados em relação às suas médias nas três siderúrgicas, mas com médias um pouco menores que a DE (esse resultado trouxe conclusões importantes para o estudo). Nesses casos, houve ainda um aumento do desvio padrão em relação à média quando comparada com a dimensão econômica. Percebeu-se que as três empresas são vistas por suas comunidades como de alto valor de marca, éticas, seguidoras das leis, filantrópicas e, principalmente, como instituições que têm o ganho econômico como finalidade.

Como primeira etapa de avaliação da validade do instrumento de pesquisa, procedeu-se à avaliação da dimensionalidade dos construtos, aplicando-se a técnica de análise fatorial com extração por componentes principais, objetivando identificar o número de fatores que determinam uma parcela considerável da variação nos dados, retendo fatores com autovalores superiores a 1. Visando avaliar se essa técnica era adequada, calculou-se a medida de Mekyser-Meyer-Olkim (KMO) de adequação da amostra, cujos valores deveriam ser superiores a 0,6 em cada subamostra (HAIR et al., 1998). É relevante ainda avaliar se a solução fatorial foi capaz de explicar ao menos 50\% da variância dos construtos, apesar de o valor $60 \%$ ser considerado o mais adequado nesse contexto (HAIR et al., 1998). Espera-se com isso que as comunalidades sejam de, ao menos, $40 \%$, evidenciando que uma parcela considerável da variância dos indicadores é explicada pela solução fatorial (DUNN; SEAKER; WALLER, 1994). De forma geral, os resultados apontaram que, para obter soluções unidimensionais, não era necessário realizar a purificação das escalas.

Com o intuito de avaliar a confiabilidade das medições, procedeu-se à análise de consistência interna por meio do alfa de Cronbach, em que o recomendável é um alfa superior a 0,6 para novas escalas. Considerando tal patamar, notou-se que os construtos apresentam confiabilidade adequada, exceto a da EMPRESA B, que ficou um pouco abaixo do mínimo aceitável - preferiu-se assim manter todos os construtos e indicadores.

Em seguida, avaliou-se a validade convergente dos construtos, empregando-se a Análise Fatorial Confirmatória para identificar se os indicadores são significativamente relacionados aos respectivos construtos. Complementarmente, foi verificado se os construtos explicavam mais de $40 \%$ da variância dos indicadores e testou-se o modelo de mensuração 
através do método de máxima verossimilhança. Segundo o critério de significância das cargas fatoriais, todos os indicadores ainda apresentaram valores aceitáveis nas três empresas analisadas, indicando validade - a despeito dos casos de confiabilidade inferior a 40\% observados na DE da EMPRESA B -, por se tratar de uma nova escala, carente de melhorias na forma de mensuração e na própria concepção dos construtos. No geral, entretanto, pode-se assumir que existe validade convergente nas medidas, pois observou-se uma possível equivalência métrica entre os modelos de mensuração.

0 componente discriminante da validade foi o segundo avaliado, buscando-se evidências de que as escalas medem conceitos diferenciados. Os resultados demonstram que embora alguns casos isolados não tenham apresentado critérios favoráveis, considerando-se o intervalo de confiança de 95\%, os construtos apresentam validade discriminante com correlações inferiores a uma unidade.

0 terceiro e último componente de avaliação da validade é conhecido como cadeia nomológica, ele visa contrastar os dados obtidos com hipóteses levantadas na literatura através da modelagem de equações estruturais, aplicando-se o método de máxima verossimilhança. Notou-se pela estrutura do modelo concebido haver pesos de regressão iguais à unidade para os indicadores dos construtos exógenos e endógenos - como também que o construto VM tem como indicadores dois outros construtos de segunda ordem reflexivos - impedindo o cálculo da significância do peso do VM para as dimensões QUA e AM. Fixando a variância do erro de previsão, tornou-se necessária a estimação somente da parcela explicada de variação com vistas a identificar o modelo. Assim, procedeu-se a uma análise de multigrupos, onde todos os parâmetros foram estimados de forma independente, o qual se denomina modelo irrestrito (TABACHNICK; FIDELL, 2001). Além disso, como nesse estudo existem mais de dois grupos, implementaram-se testes post hoc para identificar quais diferenças entre eles eram significativas. Os resultados mostraram que o modelo de mensuração dos construtos difere por empresa, exceto para a DE - o que evidenciou ser este o único conceito que tem significado similar dentre os grupos analisados. Quanto às demais dimensões, houve percepções diferenciadas nos segmentos quanto às avaliações - o que pode ser resultado da forma de relacionamento das empresas com as comunidades, de características culturais distintas ou mesmo da percepção diferenciada da imagem dessas instituições por tais comunidades. As Figuras 2, 3 e 4 mostram os resultados observados em cada empresa no tocante às seis dimensões investigadas.

Da análise dos resultados do modelo nas empresas A, B e C observam-se diferenças expressivas no efeito que as dimensões DE, DET, DL e DF de RSC têm sobre o VM, embora as diferenças observadas no valor para as dimensões QUA e AM tenham sido relativamente menores que as outras quatro. As Figuras 2, 3 e 4

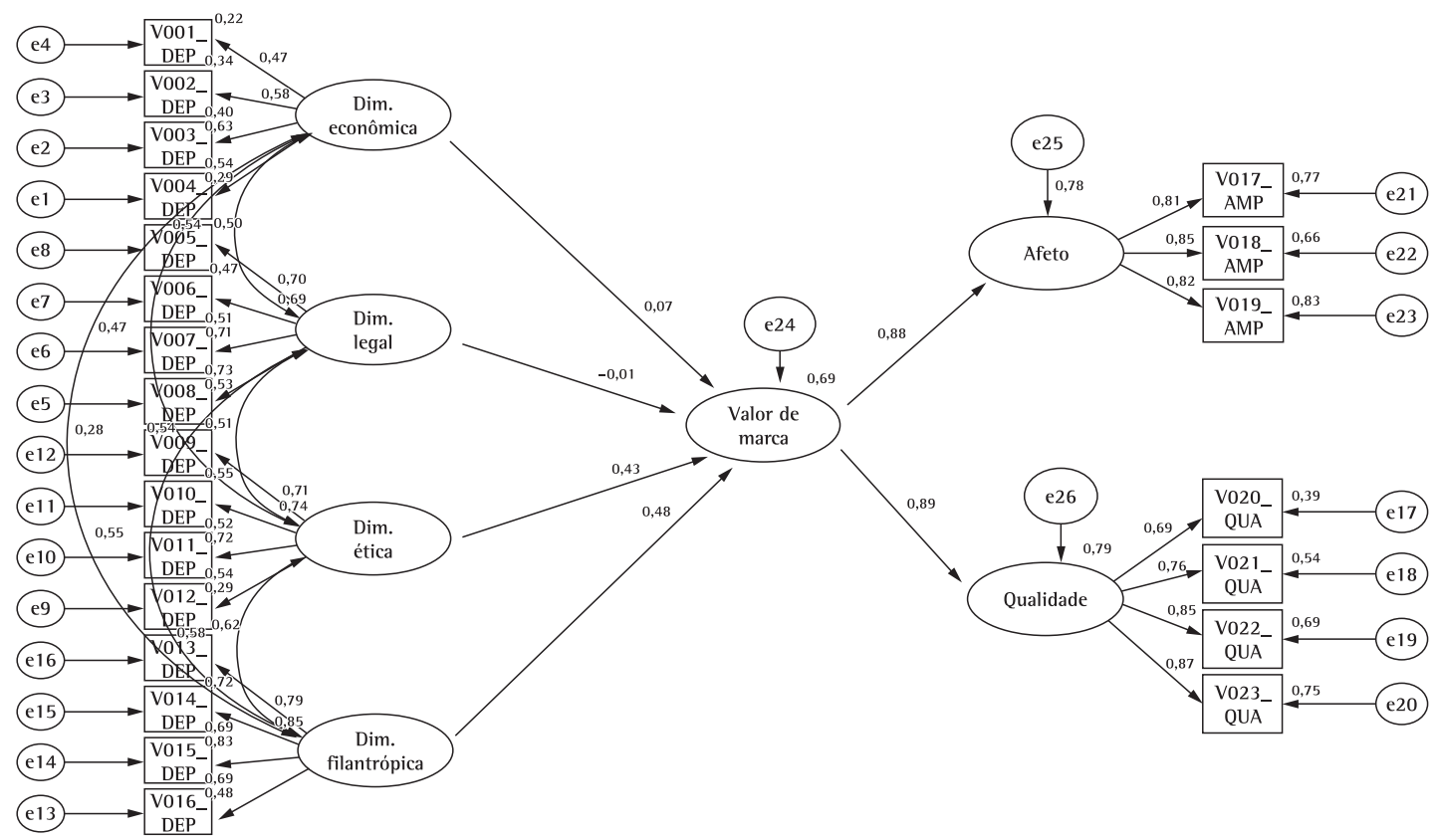

Figura 2. llustração do modelo testado: EMPRESA A. Fonte: Dados da pesquisa. 
demonstram precedentes de que o percentual de variância explicada do construto VM variou dentre os grupos analisados: na EMPRESA A as dimensões explicaram 69\% da percepção desse valor, na EMPRESA B, explicaram 75\% e, na EMPRESA C, 78\%. Assim, conclui-se que as empresas analisadas diferem bastante em termos de explicação da percepção do VM pelas comunidades de seu entorno. Em última instância, apresentam-se os ajustes do modelo final obtido e nos pesos do modelo estrutural e mensuração (Tabela 2).

A Tabela 2 mostra os pesos padronizados e não padronizados dos modelos finais encontrados para cada empresa usando a abordagem de multigrupos, e os resultados mostram o impacto relativo dos construtos

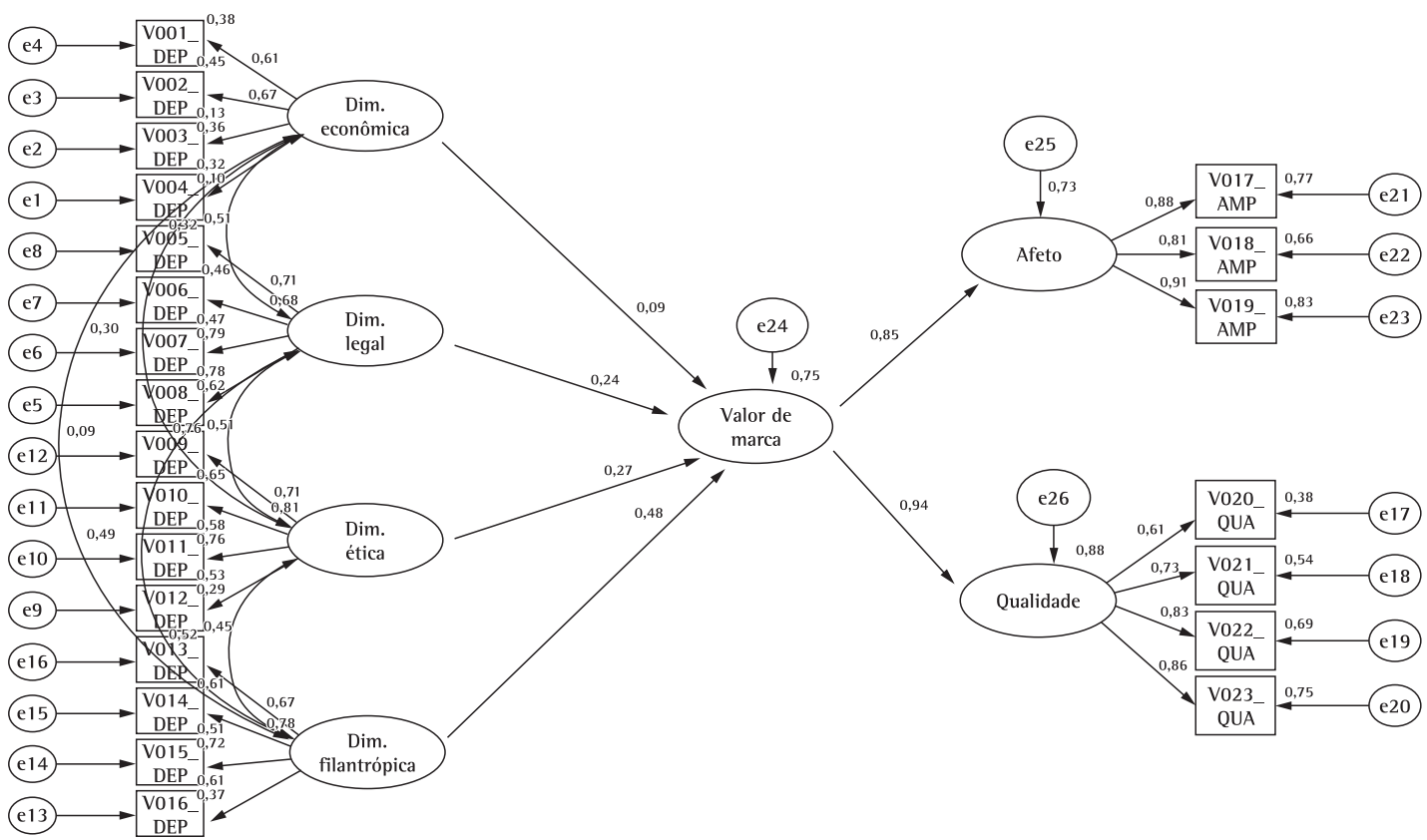

Figura 3. llustração do modelo testado: EMPRESA B. Fonte: Dados da pesquisa.

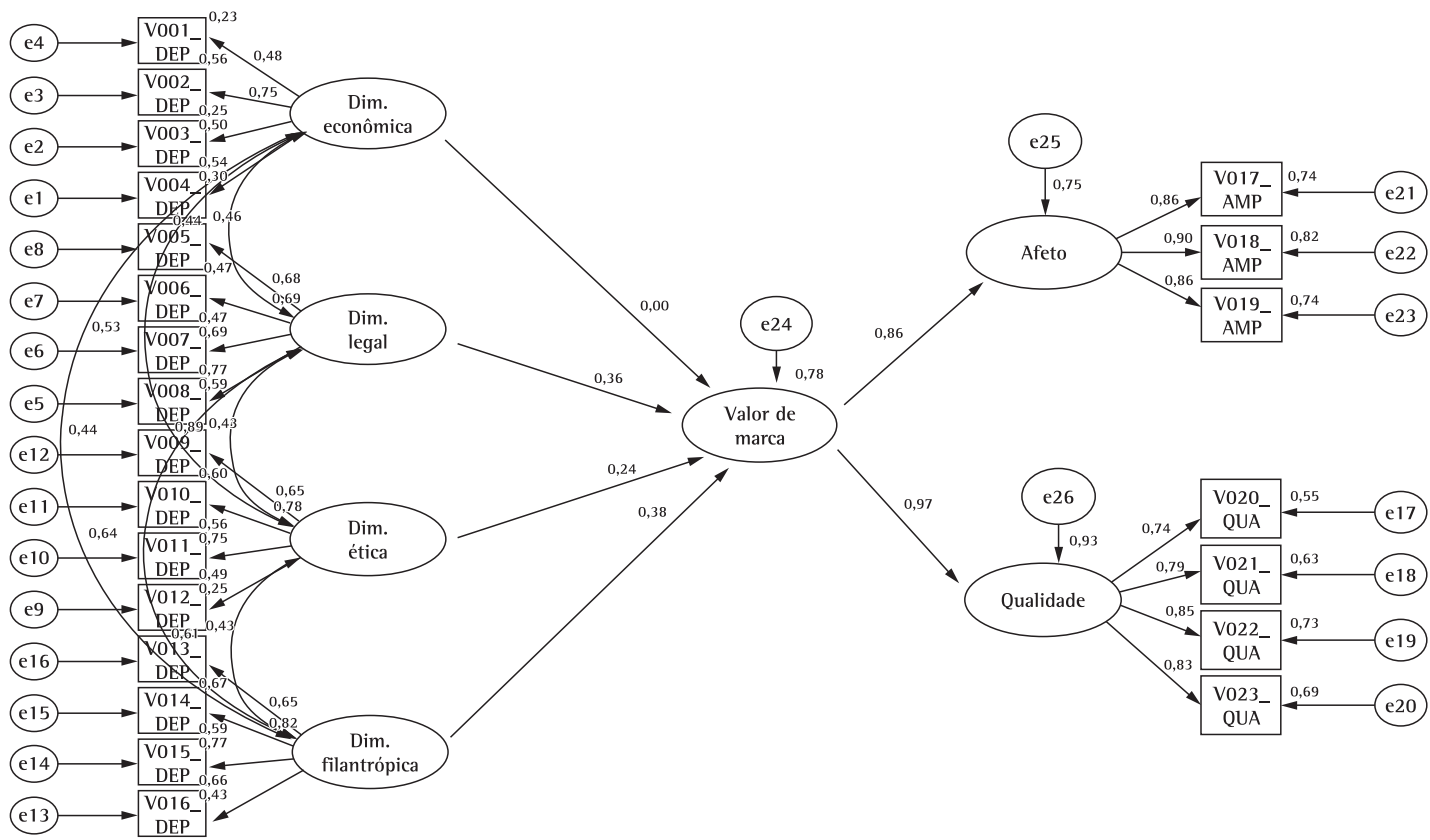

Figura 4. llustração do modelo testado: EMPRESA C. Fonte: Dados da pesquisa. 


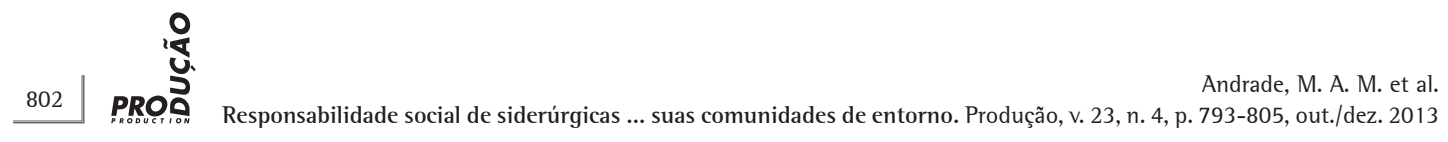

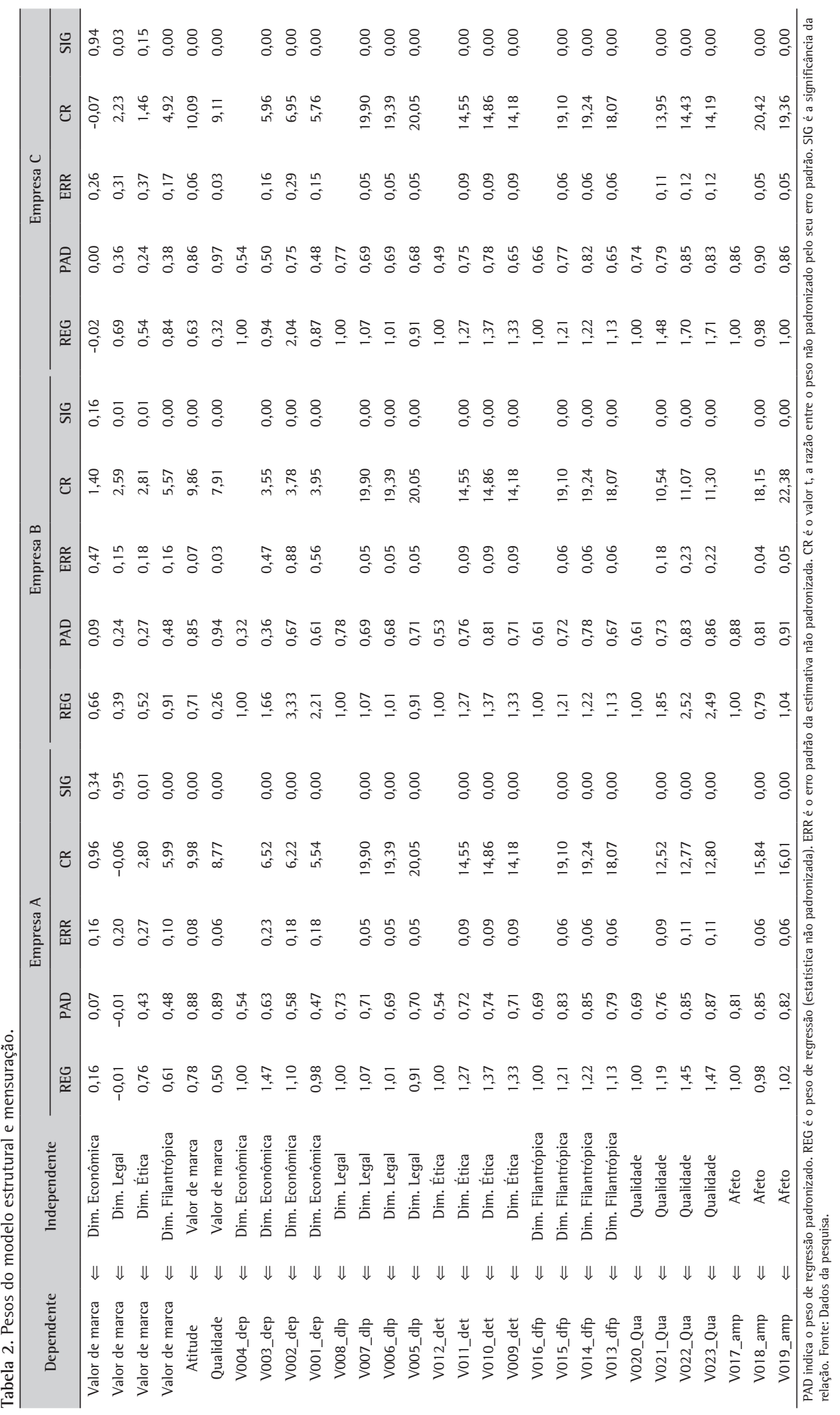


Quadro 2. Teste de hipóteses proposto no estudo.

\begin{tabular}{|c|c|c|c|}
\hline Hipóteses & Empresa A & Empresa B & Empresa C \\
\hline $\begin{array}{c}\text { Existe um impacto } \\
\text { positivo da DE } \\
\text { sobre o VM }\end{array}$ & Rejeitada & Rejeitada & Rejeitada \\
\hline $\begin{array}{c}\text { Existe um impacto } \\
\text { positivo da DL } \\
\text { sobre o VM }\end{array}$ & Rejeitada & Suportada & Suportada \\
\hline $\begin{array}{c}\text { Existe um impacto } \\
\text { positivo da DET } \\
\text { sobre o VM }\end{array}$ & Suportada & Suportada & Rejeitada \\
\hline $\begin{array}{c}\text { Existe um impacto } \\
\text { positivo da DF } \\
\text { sobre o VM }\end{array}$ & Suportada & Suportada & Suportada \\
\hline
\end{tabular}

Fonte: Dados da pesquisa. Obs: As hipóteses nulas são sempre as de igualdade entre os parâmetros analisados.

independentes e dependentes do modelo, assim como a significância de cada peso. Os resultados estatísticos apresentados nas Figuras 2, 3 e 4, bem como os ajustes do modelo final, corroboram a validade da pesquisa Survey realizada para este estudo, assim como do modelo constituído a partir desse levantamento. Eles também apresentam os parâmetros necessários para demonstrar que do ponto de vista estatístico a pesquisa tem a validade necessária para se chegar a conclusões satisfatórias - apesar de não ter sido possivel expandir os resultados para um modelo global, provavelmente em função das peculiaridades de cada caso. Dessas análises observaram-se ainda alguns índices de ajuste do modelo multigrupos propostos por Hair et al. (1998) que demonstram que, como os construtos têm variâncias diferentes, as empresas precisam ser analisadas separadamente.

Finalmente, para fechar a análise nomológica, apresenta-se no Quadro 2 o teste de hipóteses, conforme proposto na pesquisa.

\section{Considerações finais}

As análises indicaram que a EMPRESA A possui um alto valor de marca em sua comunidade, o que confirma a premissa 2, e é percebida como socialmente responsável. Verificou-se que a DET e a DF influem muito positivamente no VM, o que confirma as hipóteses 3 e 4; e que a DE e a DL não influenciaram, rejeitando as hipóteses 1 e 2 . Observaram-se fortes indícios, portanto, de que a organização tem conseguido a meta de fortalecer sua imagem dando ênfase principalmente a valores éticos e filantrópicos - o que confirma a eficácia da estratégia de comunicação das organizações (ANDRADE; GOSLING; XAVIER, 2010). Adicionalmente, constatou-se que a comunidade de entorno vê a DE como a mais bem preenchida, o que refuta a premissa 1.
Os resultados também demonstraram que a EMPRESA B possui um VM bastante positivo, o que confirma a premissa 2. A percepção da comunidade é de que ela é uma empresa socialmente responsável e que tem os aspectos éticos e filantrópicos como fortes influenciadores no VM, confirmando as hipóteses 3 e 4. Verificou-se nessa empresa que houve um impacto positivo da DL sobre o VM, o que confirma a hipótese 2, e um impacto baixo da DE sobre o VM, rejeitando a hipótese 4. De maneira similar, verificou-se que a EMPRESA C é percebida como socialmente responsável e que possui um alto VM entre a comunidade de seu entorno, confirmando a premissa 2. A exceção nesse caso foi a influência que as quatro dimensões de Carroll (1991) têm sobre o VM, tendo em vista que os fatores que mais influenciaram foram o filantrópico e o legal, o que confirmou as hipóteses 2 e 4 e rejeitou as hipóteses 1 e 3. Destaca-se, ainda, que assim como aconteceu com a EMPRESA A, a DE foi vista pela comunidade das empresas B e C como a mais bem preenchida, não sendo, assim, confirmada a premissa 1 .

Em relação às médias de resposta dos construtos qualidade e afeto, observou-se que as empresas possuem uma boa imagem de marca perante as comunidades, indicando que alcançam seus objetivos estratégicos de serem bem reconhecidas nessas localidades. Além disso, as empresas foram compreendidas como socialmente responsáveis, éticas, filantrópicas e compromissadas com a legislação. lsso demonstra que as empresas têm conseguido alcançar boa parte das suas metas estratégicas em relação às comunidades quanto a ter um alto VM - bastante influenciado pelas dimensões da RSC - e uma boa imagem nessas comunidades. A exceção aconteceu na DE das três empresas e na DL da EMPRESA A - conforme teste de hipóteses. Vale ressaltar que a influência da DET e da DF na construção do VM das empresas A e B é preponderante, corroborando a literatura analisada. Em relação à EMPRESA C, essas dimensões também têm grande influência no VM, mas a DL foi a que mais influenciou no VM.

0 estudo demonstra, portanto, que entre as siderúrgicas analisadas há uma correlação positiva entre a imagem de empresa socialmente responsável e o alto valor de marca.

Há de se destacar, no entanto, que o modelo não permite avaliar as causas que levam as pessoas a enxergarem as empresas como socialmente responsáveis. Salienta-se que a imagem que as pessoas consultadas têm das organizações é formada por uma série de variáveis que influem nessa relação. Se a siderúrgica gera empregos e riqueza satisfatória para a sociedade, por exemplo, isso pode - e muito provavelmente irá - influenciar na forma como as 
pessoas percebem essa organização do ponto de vista da RSC. Uma imagem de empresa socialmente responsável, assim, não se constituirá apenas por projetos específicos de responsabilidade social, mas por todo acontecimento do dia a dia presente no relacionamento entre a empresa e sua comunidade. Esse modelo, portanto, é bastante útil na função de diagnóstico de imagem de marca e sua relação com a percepção das variáveis da RSC, mas não possibilita inferências sobre as causas pelas quais as pessoas de uma comunidade constroem a imagem de uma empresa.

Outro fator a se salientar é que o modelo se mostrou parcimonioso, por ser de aplicação simples e ao mesmo tempo de boa fidedignidade, diferentemente de modelos teóricos baseados em estatística descritiva que não trabalham com a concepção de construtos e muito menos realizam correlações que trazem informações importantes sobre percepção de RSC e valor de marca. Percebeu-se, assim, que houve um ganho em termos de inovação teórica e gerencial, uma vez que não foram encontradas outras modelagens que trabalham esse tipo de relação. Destaca-se ainda que o modelo foi construído a partir de outros três parâmetros teóricos, testados com resultados satisfatórios em contextos internacionais, mas que avaliaram separadamente as dimensões de RSC e de valor de marca - o que reforça a contribuição teórica da pesquisa. Seria interessante, contudo, que essa metodologia fosse testada em outros contextos, a fim de verificar sua consistência como referência teórica.

Outro ponto importante é que este artigo é parte complementar de outra pesquisa, que visou avaliar como duas siderúrgicas aqui analisadas se comportam na sua comunicação corporativa em relação a suas políticas de RSC, também a partir dos pressupostos de Carroll (1991). 0 estudo anterior (ANDRADE; GOSLING; XAVIER, 2010) sugere, a partir de uma rígida análise de conteúdo dos balanços sociais corporativos (também conhecidos por relatórios de sustentabilidade) das siderúrgicas A e B, que as empresas se preocupam muito mais em salientar suas esferas éticas e filantrópicas. Comparando-se os resultados deste estudo ao anterior, percebem-se fortes indícios de que as organizações têm conseguido alcançar seus objetivos estratégicos de serem percebidas como primordialmente éticas e filantrópicas, assim como de terem uma imagem de marca positiva. Interessante ainda observar que o estudo anterior demonstra uma despreocupação das empresas com a transparência e prestação de contas de fato, assim como de destacar a busca por lucro, exatamente o contrário da percepção das comunidades. Esse resultado deve ser ressaltado, pois há pouquíssima ênfase no discurso das siderúrgicas sobre suas finalidades de ganho financeiro e muito destaque para suas boas intenções socioambientais e preocupações éticas.

Essas comparações sugerem reflexões mais sérias acerca da RSC. Elas indicam que as organizações precisam ser mais claras na sua veiculação publicitária sobre suas intenções acerca da responsabilidade social corporativa. Ao que parece, uma atitude realmente transparente pode ser mais coerente com aquilo que as pessoas vêm percebendo sobre as reais motivações dessas estratégias.

\section{Referências}

ADKINS, S. Marketing de Causas Sociais: quem se importa, vence. In: BAKER, M. Administração de Marketing. Rio de Janeiro: Ed. Campus, 2005. cap. 26.

ANDRADE, M.; GOSLING, M.; XAVIER, W. Por trás do discurso socialmente responsável da siderurgia mineira. Produção, v. 20, n. 3, p. 418-428, 2010. http://dx.doi.org/10.1590/ S0103-65132010005000014

ASHLEY, P. A. Ética e responsabilidade social nos negócios. São Paulo: Saraiva, 2002.

BORGES, F. G. Responsabilidade Social: efeitos da atuação social na dinâmica empresarial. 2001. Tese (Doutorado)Universidade de São Paulo, São Paulo, 2001.

BITTENCOURT, E.; CARRIERI, A. Responsabilidade Social: Ideologia, Poder e Discurso na Lógica Empresarial. RAE, v. 45, p. 10-22, 2005. Edição especial.

CARROLL, A. Corporate social responsibility: evolution of a definitional construct. Business and Society, vol. 38 , p. 268-295, 1999 . http://dx.doi. org $/ 10.1177 / 000765039903800303$

CARROLL, A. B. The pyramid of corporate social responsibility: toward the moral management of organizational stakeholders. Business Horizons, v. 34, n. 4, p. 39-39, 1991. http://dx.doi.org/10.1016/00076813(91)90005-G

CARROLL, A. B. Corporate Social Responsibility: Will Industry Respond to CutBacks in Social Program Funding. Vital Speeches of the Day, v. 49, p. 604-608, 1983.

DUNN, S. C.; SEAKER, R. F.; WALLER, M. A. Latent variable in business logistics research: scale development and validation. Journal of Business Logistics, v. 15, n. 2, p. 145-173, 1994.

DRUCKER, P. F. The new meaning of corporate social responsibility. California Management Review, v. 26, p. 53-63, 1984. http://dx.doi.org/10.2307/41165066

FEDERAÇÃO DAS INDÚSTRIAS DE MINAS GERAIS - FIEMG. Disponível em: <www.fiemg.com.br>. Acesso em: jan. 2009.

GUIMARÃES, A. Marketing Verde e a Propaganda Ecológica: Uma análise da estrutura da comunicação em anúncios impressos. 2006. Tese (Doutorado)-Universidade de São Paulo, São Paulo, 2006.

HAIR J. J. F. et al. Multivariate data Analysis. 5th ed. Upper Saddle River: Prentice Hall, 1998.

JONES, T. M. Corporate social responsibility revisited, redefined. California Management Review, v. 22, n. 3, p. 59-67, 1980. http://dx.doi.org/10.2307/41164877 
JORNAL ESTADO DE MINAS. A China é aqui!. Jornal Estado de Minas, Caderno de Economia, 09 dez. 2007.

KELLER, K. L. Conceptualizing, measuring and managing customer-based Brand Equity. Journal of Marketing, v. 57, n. 1, p. 1-22, 1993. http://dx.doi.org/10.2307/1252054

KLINE, R. B. Principles and practices of structural equation modeling. New York: Guilford, 1998.

LASSAR, W.; MITTAL, B.; SHARMA, A. Mesuring Customer-based brand equity. Journal of Consumer Marketing, v. 12, n. 4, 1995 . http://dx.doi. org/10.1108/07363769510095270

LAVILlE, C.; DIONNE, J. A Construção do Saber. Belo Horizonte: Ed. UFMG, 2007.

LINDQUIST, J. D. Meaning of image: a survey of empirical and hypothetical evidence. Journal of Retailing, v. 50, n. 4, p. 29-39, 1975.

MingoTl, S. A. Análise de Dados Através de Métodos de Estatística Multivariada: uma abordagem aplicada.Belo Horizonte: Editora UFMG, 2005.

OLIVEIRA, J. A. P. Uma avaliação dos balanços sociais das 500 maiores. RAE Eletrônica, v. 4, n. 1, 2005. http://dx.doi. org/10.1590/S1676-56482005000100002

PESTANA, M. H.; GAGEIRO, J. N. Análise de Dados para Ciências Sociais - Complementaridade do SPSS. 2. ed. Lisboa, 2000.

SERPA, D. Efeitos da Responsabilidade Social Corporativa na Percepção do Consumidor Sobre Preço e Valor. Um Estudo Experimenta. 2006. Tese (Doutorado)-Instituto
COPPEAD de Administração, Universidade Federal do Rio de Janeiro, Rio de Janeiro, 2006.

SOARES, G. M. P. Responsabilidade social corporativa: por uma boa causa!?. RAE Eletrônica, v. 3, n. 2, Art. 23, jul./dez. 2004. http://dx.doi.org/10.1590/S167656482004000200007

SROUR, R. H. Ética Empresarial: Posturas Responsáveis nos Negócios, na Política e nas Relações Sociais. São Paulo: Ed. Campus, 2003.

TABACHNICK, B. G.; FIDELL, L. S. Using Multivariate Statistics. 4th ed. New York: HarperCollins, 2001.

TENÓRIO, F. et al. Responsabilidade Social Empresarial. 2. ed. Rio de Janeiro: Editora FGV, 2006.

TOFFLER, A. A empresa flexível. Rio de Janeiro: Ed. Record, 1995.

TREVISAN, F. A. Balanço Social Como Instrumento de Marketing. RAE Eletrônica, v. 1, n. 2, jul./dez. 2002. http://dx.doi.org/10.1590/S1676-56482002000200017

WILKIE, W.; MOORE, E. Marketing's contributions to society. Journal of Marketing, p. 198-218, 1999. http://dx.doi. $\operatorname{org} / 10.2307 / 1252112$

YOO, B.; DONTHU, N. Developing and Validating a Multidimensional Consumer-based Brand Equity Scale. Journal of Business Research, v. 52, p. 1-14, 2001. http://dx.doi.org/10.1016/S0148-2963(99)00098-3

\section{The social responsability of steel companies from Minas Gerais State (Brazil) and the perception of their surrounding communities} Abstract

The main purpose of this paper was to evaluate the perception of three surrounding communities of large steel companies from the State of Minas Gerais about the social responsibility of these corporations, as well as the relationship between this perception and the brand value view (BV). The study used the framework "Pyramid of Social Responsibility”, proposed by Carroll (1991). It was a quantitative survey research with likert-type questions, which aimed to assess how the communities perceive the various aspects of the social responsibility of these organizations and the perception of their brand value, as well as the relationship between these factors. The results, which were analyzed by multivariate statistical methods, showed that the analyzed companies have high quality brand values, mainly due to a positive perception of their ethical and philanthropic dimensions.

\section{Keywords}

Brand equity. Social responsibility. 